\title{
Article
}

\section{Fertility Outcomes, Heritability and Genomic Associations of In-Group Preference and In-Group Marriage}

\author{
Martin Fieder ${ }^{1,2}$ and Susanne Huber ${ }^{1,2}$ \\ ${ }^{1}$ Department of Evolutionary Anthropology \& Network of Human Evolution and Archeological Sciences, University of Vienna, Vienna, Austria and ${ }^{2}$ Centre \\ 'Religion and Transformation in Contemporary Society', University of Vienna, Vienna, Austria
}

\begin{abstract}
Using data from the Midlife Development in the USA (MIDUS) sample (3070 men and 3182 women) and the Wisconsin Longitudinal Study (WLS; 2240 men and 2346 women), we aimed to investigate whether religious, ethnic and racial in-group preferences as well as religious homogamy are associated with reproductive outcome in terms of number of children. Using data from the MIDUS twin sample, we further estimated the inherited genetic component of in-group attitudes. Additionally, we analyzed the association of 50 polygenic scores (PGSs) recently published for the WLS study and in-group attitudes as an indicator of potential pleiotropic effects. We found in both samples that, with one exception, religious though not other in-group attitudes are associated with a higher reproductive outcome. Also, religious homogamy is associated with higher average number of children. The inherited component of all in-group attitudes ranges from $\sim 21 \%$ to $45 \%$ (MIDUS twin sample). PGSs associated with religious behavior are significantly positively associated with religious in-group attitudes as well as family attitudes. Further associations are found with PGS on life satisfaction (work) and, negatively, with PGS for any sort of addiction (smoking, alcohol and cannabis use), indicating pleiotropy. We conclude that the positive association between religious in-group attitudes as well as religious homogamy and reproductive outcome may indicate selective forces on religious in-group behavior. As all investigated ingroup attitudes, however, have a substantial inherited component, we further speculate that potential previous reproductive benefits of racial and ethnic in-group preferences, if they ever existed, might have been substituted by religious in-group preferences.
\end{abstract}

Keywords: In-group favouritism and homogamy; reproduction; heritability; evolution; polygenic scores

(Received 7 October 2021; accepted 8 November 2021)

In-group and out-group attitudes and values are a strong force shaping our political systems in Europe, particularly since the onset of the so-called 'migration crises' in the year 2015 and beyond (Hampshire, 2015). As the main part of our evolution has taken part in small-scale societies within small groups mostly consisting of kin, encounters with groups of strangers may have led to different outcomes, ranging from violent outbreaks as documented for recent tribal societies (Chagnon, 2013) as well as from archaeological records (e.g., Stone Age massacres) and large-scale genetic data (Reich, 2018) to peaceful genetic (e.g., intergroup marriages; Sikora et al., 2017) and cultural exchange, such as the invention of the wheel, horse riding, warrior's chariot and many other further developments (Anthony, 2010; Schahbasi et al., 2021). We assume that this long history of hostility and exchange did influence our psychological make-up and thus our individual predisposition to what extent we are xenophilic versus xenophobic. Particularly, differences in in-group versus out-group attitudes between men and women may point to evolutionarily acquired predispositions: the friendlier attitude of particularly young women may reflect frequent female dispersal and out-group

Author for correspondence: Martin Fieder, Email: martin.fieder@univie.ac.at Cite this article: Fieder M and Huber S. (2021) Fertility Outcomes, Heritability and Genomic Associations of In-Group Preference and In-Group Marriage. Twin Research and Human Genetics 24: 264-272, https://doi.org/10.1017/thg.2021.48 marriage (Huber et al., 2017), thus fostering genetic and cultural exchange; the more restrictive attitude of men may indicate a predisposition to avoid potentially lethal violence, affecting particularly men, as documented by the high ratio of male victims in prehistoric outbreaks of violence (Glowacki \& Wrangham 2015; Goldberg et al., 2017; Haak et al., 2015; Jantzen et al., 2011) as well as by the near extinction of resident male genomes during periods of mass migration (Reich, 2018). Thus, a more open 'xenophilic attitude' more frequently found among young women (Schahbasi et al., 2021) may have helped to avoid inbreeding and cultural stagnation, whereas a more closed 'xenophobic attitude' found more frequently among men may have helped to avoid potentially lethal encounters among human groups.

In order to evolve, a trait should be associated with reproduction, and previous studies have shown that this is presumably true for in-group attitudes, particularly for in-group marriage (Fieder \& Huber, 2016; Huber \& Fieder, 2011, 2016). Accordingly, favoring the in-group should be associated with having more children. Moreover, in order to evolve, attitudes also must have a genetic basis. Correspondingly, studies have shown that in-group favoritism has in part a genetic, heritable basis. The variance in in-group favoritism' explained by inheritance varies greatly from $18 \%$ to $79 \%$ depending on the actual trait surveyed and how the in-group has been defined (Kandler et al., 2015; Lewis et al., 2014; Loehlin, 1993). The stability of in-group versus out-group attitudes during 
the course of life further underpins a genetic basis (Lewis \& Bates, 2017).

In-group attitudes may be reflected by in-group marriage. Indeed, homogamy within race, ethnicity and religion (Carlson, 2019; Heaton, 1984; Huber \& Fieder, 2018; Kalmijn, 1991) and more recently, education (Carlson, 2019; Fieder \& Huber, 2016; Huber and Fieder, 2011) is common, as shown, for instance, in the USA (Carlson, 2019). Particularly with regard to religion, marriage rules often enforce homogamy as shown in the Bible in the Book of Deuteronomy 7, 3: 'Do not take wives or husbands from among them [the disbelieving]; do not give your daughters to their sons or take their daughters for your sons'; and in the Quran 2, 221: 'And do not marry polytheistic women until they believe.' These rules also make sense from an evolutionary point of view as with some exceptions, couples who marry within their own religious denomination have, on average, more children and remain childless less frequently than couples marrying outside their own denomination (Fieder \& Huber, 2016). Also, educational homogamy, which is increasingly gaining importance, is associated with lower childlessness though not a higher number of children (Huber \& Fieder, 2011, 2016; van Bavel, 2012). However, it has to be kept in mind, that the positive effects of homogamy on reproduction may be counterbalanced by negative inbreeding effects (Clark et al., 2019), particularly in smallscale societies.

In line with these findings, we aim to examine whether in-group preference according to religion, ethnicity and race and other indicators of 'in-group preference', as well as in-group marriage, are associated with reproductive output. In addition, we aim to determine the heritability of in-group attitudes and in-group marriage on the basis of a twin sample. We further analyze the association of newly available polygenic risk scores and traits reflecting in-group preferences and in-group marriage.

\section{Methods}

We first analyzed whether in-group favoritism as well as in-group homogamy are associated with the number of children. We used the MIDUS dataset (Midlife Development in the USA; http:// midus.wisc.edu/scopeofstudy.php\#History) and the Wisconsin Longitudinal Study (WLS) for this analysis.

The MIDUS survey in the USA is a longitudinal study first conducted in 1995-96 by the MacArthur Foundation Research Network on Successful Midlife Development. The aim of the study is to investigate the role of behavioral, psychological and social factors in accounting for age-related variations in health and wellbeing in a national sample of Americans.

For the analysis of the effects of in-group preference and ingroup marriage on reproduction, we only included unrelated individuals (in the case of twins, we only included one twin); in total, 6252 individuals ( 3070 men and 3182 women) aged over 45 years who thus have almost completed reproduction.

We included the following variables in our analysis: $\operatorname{sex}(1=$ male, 2 = female), children ever born, highest education (supplementary Table S1); wages (supplementary Table S2), age at interview as well as the following nine 'attitude' variables (abbreviated as 'ATVm') reflecting the attitudes to religious, ethnic and racial in-group preferences, each surveyed on a 4-item Likert-type scale: (1) Identify with your religious group; (2) Prefer people of same religion; (3) Important to marry in same religion; (4) Closely identify with the same ethnicity; (5) Prefer to be with same ethnicity; (6) Important to marry the same ethnicity; (7) How closely identify with same race; (8) How much prefer to be with same race; (9). How important to marry same race. The original variables had been encoded with the lowest values for the strongest agreement. For easier interpretation of statistical models, we reversed this order (supplementary Table S3: $1=$ not at all important at all up to $4=$ very important).

We first investigated if there is an association of the ATVms with the individual demographic characteristics sex (encoded as $1=$ male, 2 =female), age in years, education (codes see supplement Table S1) and wages of the study participants, with family ID and race as random factors, applying separate mixed ordinal models for each ATVm implemented in the R library ordinal, function clmm. To investigate the association of ingroup attitudes and reproduction, we further calculated the following models separately for each ATVm: number of children regressing on sex, age at interview, education, wages, regressing on each of the ATVm's on the basis of a Poisson error structure. As the MIDUS sample also includes non-Whites and individuals belonging to a family, we calculated all the models using mixed modeling with family ID and race as random factors. To avoid any confounded results, we also calculated the models for only Whites and nonfamily; however, the principal results did not change.

As the MIDUS dataset also includes twins, we further investigated the heritability of in-group preference and homogamy, including the data of 159 male and 181 female monozygotic twin pairs, 108 male and 184 female dizygotic twin pairs, as well as 220 different sex dizygotic twin pairs, aged between 25 and 74 . As heritability estimates are comparable if all twin pairs $(N=852)$ or only white twin pairs are included $(N=721)$, we included all individuals irrespective of race in all further analysis.

To estimate the heritability of the ATVms, we used the R-library UMX 3.4 (CRAN-Package umx; r-project.org) to perform a separate ACE Cholesky model for each of the ATVms with sex and age at interview as covariates. Further, we calculated the $\mathrm{MZ}$ versus DZ twin correlations.

The WLS is a long-term study of a random sample of men and women who graduated from Wisconsin high schools in 1957 and their siblings. The WLS panel started out with 10,317 members from the class of 1957. In the year 2010, variables on attitudes were surveyed. We included the following attitude variables (further abbreviated as ATVw) reflecting the attitude to in-group preference in our analysis: (1) How important is identity; (2) How close is own religious group; (3) How important is it to marry the same religion; (4) How important is religious identity; (5) How important are people of the same religion; (6) How important is your voluntary identity; (7) How important is your political identity; (8) How important is your work identity; (9) How important is your organizational identity; (10) How important is ethnic and national identity (the variables are encoded as $1=$ not at all, $2=$ not very, $3=$ somewhat, $4=$ very, $5=$ extreme). Additionally, we included the following variables: whether or not the spouse has the same religion $(0=$ not the same religion, $1=$ same religion $)$, $\operatorname{sex}(1=$ male, $2=$ female $)$, year of birth and the number of biological children. In total, we included 2240 White men and 2346 White women in our analysis.

As in the MIDUS dataset, we regressed each ATVw separately on sex, year of birth and education using separate ordinal models, implanted in the R-library ordinal, function clmm. We further regressed the number of children on each of the attitude variables ATVws, controlling for family, sex, education (supplementary Table S6) and birth year on the basis of a Poisson error structure. 
Recently, WLS has provided a bundle of polygenic scores (PGSs; Benjamin et al., 2021) from various genomewide association studies (GWAS) for the WLS graduates as well as for the siblings on the basis of 23andMe and the UK Biobank (as has been published by WLS). The PGSs are based on summary statistics from three sources: GWAS conducted on the basis of 23 andMe, UK Biobank and other published GWAS papers. The PGSs were calculated using LDpred that has been applied to HapMap3 SNPs. The inclusion criterion was an out-of-sample predictive power of a PGS greater than $1 \%$. On the basis of these data, we aimed to investigate whether ATVws are associated with each of these PGSs, given a Gaussian error structure. Although multivariate PGSs, also provided by WLS, may lead to more and higher significances, we decided to use the single primary PGS, as multivariate PGSs are subject to additional confounding factors (Benjamin et al., 2021). We regressed each ATVw on sex, birth year, each single PGS, the 10 first principal components of population structure, as well as the corresponding ATVws for a selected sib to control for 'nature by nurture' (Mills et al., 2020) and as recommended by Benjamin et al. (2021). In total, we included the data of 2713 White men and 2980 White women born between 1937 and 1940 and used each single PGS provided by WLS. We included the 10 first principal components of the population structure (PCAs) in all our PGS analyses to control for potential population stratification, as recommended by WLS. The PCAs had been calculated on the basis of the genomic data by WLS (Benjamin et al., 2021). Using the R function heatmap, we calculated a heatmap on the correlations.

\section{Results}

\section{MIDUS Dataset}

ATVm and demographics. We found significant associations between most demographic characteristics and the ATVms (Table 1): being a woman was significantly positively associated with the identification with someone's own religious group, the preference for people of the same religious group and the importance of marrying within a religious group, as well as with the closeness to someone's own race, but significantly negatively with the preference of someone's own ethnic group. Age was generally significantly positively associated with the ATVms (with one exception) and education was mostly negatively associated with the ATVms (not always significant) though significantly positively with the identification of someone's own religious group. Wages were generally significantly negative but had a tiny association with the ATVms.

ATVms and reproduction. In the MIDUS dataset, including both men and women, the ATVms towards religion were significantly positively associated with the number of children (Table 2). Each ATVm explained between $0.1 \%$ and $1.4 \%$ (in the case of Important to marry same religion) of the total variance of number of children. Age was generally significantly positively and education generally significantly negatively associated with the number of children (Table 2). If analyzed separately, in women, the pattern remained principally unchanged, whereas in men, Important to marry same race was also significantly positively associated with the number of children, variances explained were somewhat higher and wages were significantly positively associated with number of children (Supplementary Tables S4 and S5).
Heritability of ATVms. The heritability of the ATVms ranged from a low $19 \%$ (How close is own race) up to $46 \%$ (Important to marry same race) (Table 3 ). The contribution of the common environment was around 10\%, varying from $1 \%$ and lower for 'race' to $24 \%$ (Important to marry same religion). The influence of the unique environment was particularly high in the case of How close is own race (80\%) and Prefer same race (72\%). Generally, the unique environment contributed mostly to the ATVms (Table 3). Except for Prefer same race and Important to marry same race, sex always covaried positively with the ATVms; hence, being a woman was positively associated with the ATVms. Except for How close is own race, this also held true for age at interview.

\section{Wisconsin Longitudinal Study}

ATVws and demographics. Also in the WLS, we found a significant association between most demographic characteristics and the ATVws. Interestingly, most, but not all, of the ATws that were positively associated with reproduction were also positively associated with being a woman (cf. Tables 4 and 5). No significant difference between men and women was found for spouse who has the same religion and organizational and ethnic identity (Table 4). Education was usually significantly negatively associated with the ATVws except for political and work identity, and few significant associations were found for birth year.

ATVw and reproduction. In the WLS dataset, we found that the ATVws How important is family identity, How close is own religious group, How important is it to marry same religion, How important is religious identity and How important are people of the same religion, as well as being in a religiously homogamous marriage, were significantly positively associated with the number of children. Being female was significantly positively (a characteristic of the WLS dataset is that women have more children compared to men) and education was significantly negatively associated with number of children (Table 5). As we calculated several independent models and the estimates for education, sex and birth year were all in a close range, we only displayed the mean beta values from the independent models.

With $2.36 \%$, the attitude How important is family identity explained a comparable proportion of the total variance of number of children as education, followed by How close someone is to his own religious group ( $1.16 \%$; Table 5$)$. Being in a religious homogamous relationship was positively associated with the number of children, but with $.21 \%$ it explained a lower proportion of the total variance than the attitude towards a religious homogamous marriage (.78\%; Table 5). If analyzed separately for men and women, we found a comparable pattern except for the association between the Importance of voluntary identity and number of children, which was significantly positive in men and nonsignificant in women (Table S7, S8).

ATVws and PGSs. The associations of the ATVws with the PGSs showed potential pleiotropic associations. We found several associations with all ATVws with the exception of the importance of ethnic and national identity. In Figure 1, all associations are displayed. Table 6 summarizes only the PGSs where at least one significant association appears.

Expectedly, the PGS for religious participation was positively associated with some of the ATVws of religious in-group preferences. Also, the PGS for life satisfaction (work) was significantly positively associated with religious homogamy and the importance 
Table 1. ATVms regressing on demographic factors using mixed ordinal models with family ID and race as random factors. Nonstandardized regression coefficients of the linear mixed ordinal models are displayed

\begin{tabular}{|c|c|c|c|c|c|c|c|c|c|}
\hline & N & Sex & & Age & & & & Wages & \\
\hline Identify with own religious group & 2201 & 0.42 & $* * *$ & 0.02 & $* * *$ & 0.06 & $* * *$ & -0.01 & $* * *$ \\
\hline Prefer people same religion & 2200 & 0.24 & $* * *$ & 0.01 & $* *$ & -0.02 & & -0.02 & $* * *$ \\
\hline Identify with ethnic group & 1989 & 0.07 & & -0.01 & $* *$ & 0.00 & & -0.01 & $* * *$ \\
\hline Prefer ethnic group & 1988 & -0.14 & $*$ & 0.01 & $* *$ & -0.02 & & -0.01 & $* * *$ \\
\hline How close to own race & 2176 & 0.27 & $* * *$ & 0.01 & $*$ & -0.01 & & -0.01 & $*$ \\
\hline Prefer same race & 2187 & -0.09 & & 0.02 & $* * *$ & -0.09 & $* * *$ & -0.01 & $*$ \\
\hline Important to marry same race & 2187 & -0.08 & & 0.03 & ** & -0.10 & ** & 0.00 & \\
\hline
\end{tabular}

Note: ATVms, attitude variables Midlife Development in the USA [MIDUS] sample. Sex is coded as $1=$ female, $2=$ male, education and wages encoding see supplementary Tables S1, S2. ${ }^{\star}$ indicates $p$ values: ${ }^{\star}<.05,{ }^{\star \star}<.01,{ }^{\star \star \star}<.001$.

Table 2. Number of children regressing on sex, age at interview, education, wages and each of the ATVms on the basis of a Poisson error structure, with family ID and race as random factors

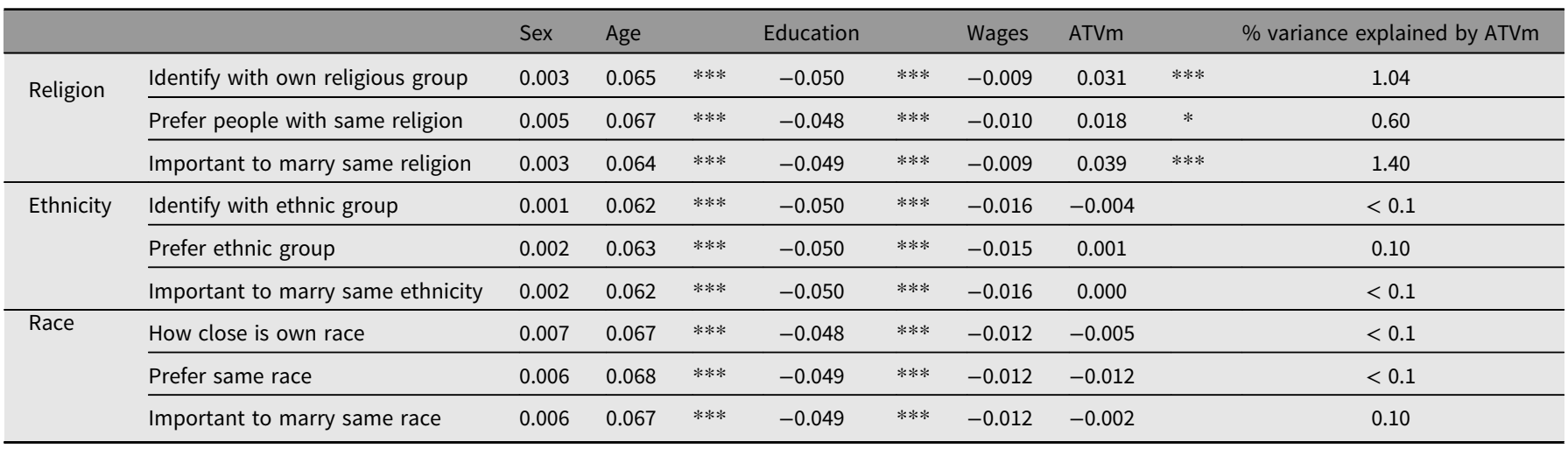

Note: ATVms, attitude variables Midlife Development in the USA [MIDUS] sample. Beta values; ${ }^{*}$ indicate $p$ values: ${ }^{\star}<.05,{ }^{\star \star}<.01,{ }^{\star \star \star}<.001$.

Table 3. ACE models, covariates and twin correlations with confidence intervals

\begin{tabular}{|c|c|c|c|c|c|c|c|c|c|}
\hline & \multicolumn{3}{|c|}{ ACE model } & \multicolumn{2}{|c|}{ Covariates } & \multicolumn{4}{|c|}{ Twin correlations } \\
\hline & $\mathrm{a} 1^{2}$ & $\mathrm{Cl}^{2}$ & $\mathrm{e} 1^{2}$ & Sex & Age Interview & Monozygotic & Confidence interval & Dizygotic & Confidence interval \\
\hline Identify with own religious group & $44 \%$ & $6 \%$ & $50 \%$ & 0.214 & 0.015 & 0.54 & $(0.45,0.61)$ & 0.28 & $(0.19,0.37)$ \\
\hline Prefer people with same religion & $35 \%$ & $9 \%$ & $56 \%$ & 0.14 & 0.007 & 0.46 & $(0.36,0.54)$ & 0.25 & $(0.16,0.34)$ \\
\hline important to marry same religion & $23 \%$ & $24 \%$ & $53 \%$ & 0.183 & 0.013 & 0.49 & $(0.40,0.57)$ & 0.36 & $(0.28,0.44)$ \\
\hline Identify with ethnic group & $39 \%$ & $0 \%$ & $61 \%$ & 0.022 & 0.007 & 0.37 & $(0.25,0.47)$ & 0.24 & $(0.13,0.34)$ \\
\hline Prefer ethnic group & $22 \%$ & $13 \%$ & $64 \%$ & 0.096 & 0.000 & 0.4 & $(0.29,0.51)$ & 0.21 & $(0.10,0.31)$ \\
\hline important to marry same ethnicity & $22 \%$ & $11 \%$ & $68 \%$ & 0.045 & 0.008 & 0.31 & $(0.19,0.43)$ & 0.22 & $(0.12,0.33)$ \\
\hline How close to own race & $19 \%$ & $1 \%$ & $80 \%$ & 0.148 & -0.001 & 0.20 & $(0.09,0.3)$ & 0.10 & $(0.01,0.20)$ \\
\hline Prefer same race & $28 \%$ & $0 \%$ & $72 \%$ & -0.005 & 0.011 & 0.31 & $(0.20,0.41)$ & 0.13 & $(0.03,0.22)$ \\
\hline Important to marry same race & $46 \%$ & $0 \%$ & $54 \%$ & -0.031 & 0.017 & 0.49 & $(0.4,0.57)$ & 0.24 & $(0.15,0.33)$ \\
\hline
\end{tabular}

of religious, family and voluntary identity. The PGS for alcohol misuse, on the other hand, was significantly negatively associated with How important are people of the same religion, How close is own religious group and How important is religious identity, which also holds partly true for the PGS of cannabis use and the PGS of having ever smoked. Generally, a PGS indicating addictive behavior is negatively associated with religious in-group preferences. Additionally, the PGS of ADHD was significantly negatively 
Table 4. ATVws regressing on sex, birth year and education applying separate ordinal models for each of the ATVws

\begin{tabular}{|c|c|c|c|c|c|c|}
\hline & Beta sex & & Bet & & Beta education & \\
\hline How important is family identity & 0.07 & $* * *$ & 0.00 & & -0.05 & $* * *$ \\
\hline How close is own religious group & 0.16 & $* * *$ & 0.00 & & -0.01 & \\
\hline Important to marry same religion & 0.07 & $* * *$ & -0.00 & & -0.03 & * \\
\hline How important is religious identity & 0.16 & $* * *$ & 0.01 & & -0.01 & \\
\hline Important people are same religion & 0.10 & $* * *$ & -0.02 & & -0.03 & $*$ \\
\hline Spouse has same religion & -0.22 & & -0.03 & & -0.19 & \\
\hline How important is voluntary identity & 0.06 & $* * *$ & 0.01 & & 0.01 & \\
\hline How important is political identity & -0.03 & * & -0.04 & $* *$ & 0.06 & $* * *$ \\
\hline How important is work identity & -0.06 & $* * *$ & 0.00 & & 0.04 & $* * *$ \\
\hline How important is organizational identity & -0.01 & & -0.03 & . & -0.02 & \\
\hline Importance of ethnic national identity & -0.01 & & -0.03 & $*$ & -0.04 & $* *$ \\
\hline
\end{tabular}

Note: ATVws, attitude variables Wisconsin Longitudinal Study. ${ }^{*}$ indicate $p$ values: ${ }^{*}<.05,{ }^{\star \star}<.01,{ }^{\star \star \star}<.001$.

Table 5. Number of children regressing in separate models on the ATVws, beta values, significances and variance explained

\begin{tabular}{|c|c|c|}
\hline & Beta values & $\begin{array}{l}\% \text { variance } \\
\text { explained }\end{array}$ \\
\hline How important is family identity & $0.057 * * *$ & 2.36 \\
\hline How close is own religious group & $0.041 * * *$ & 1.16 \\
\hline Important to marry same religion & $0.032 * * *$ & 0.78 \\
\hline How important is religious identity & $0.024 * *$ & 0.68 \\
\hline $\begin{array}{l}\text { How important are people with } \\
\text { same religion }\end{array}$ & $0.025 * * *$ & 0.51 \\
\hline Spouse has the same religion & $0.019 * *$ & 0.21 \\
\hline How important is voluntary identity & 0.008 & 0.06 \\
\hline $\begin{array}{l}\text { How important is your political } \\
\text { identity }\end{array}$ & -0.004 & 0.04 \\
\hline How important is work Identity & -0.002 & 0.02 \\
\hline $\begin{array}{l}\text { How important is your } \\
\text { organizational identity }\end{array}$ & 0.004 & 0.02 \\
\hline $\begin{array}{l}\text { How important is ethnic and } \\
\text { national identity }\end{array}$ & 0.0016 & 0.01 \\
\hline Birth year & $\sim 0.003$ & 0.02 \\
\hline Sex female (ref.: male) & $\sim 0.014 *(* *)$ & 0.47 \\
\hline Education & $\sim-0.083 * * *$ & 2.64 \\
\hline
\end{tabular}

Note: ATVws, attitude variables Wisconsin Longitudinal Study. ${ }^{*}$ indicate $p$ values: ${ }^{*}<.05$, ${ }^{\star \star}<.01,{ }^{\star * \star}<.001$.

associated with How important are people of the same religion and with Spouse has the same religion; the PGS of narcissism was significantly positively associated with How important is family identity and How important is religious identity. All the other PGSs only showed one association with any of the ATVws (Table 6).

\section{Discussion}

We found that in both datasets, in-group attitudes according to religion are associated with higher number of children, which also holds true for the preference for actual religious in-group marriage. If men and women are analyzed separately, however, in men from the MIDUS dataset, also Important to marry same race was significantly positively associated with the number of children. In addition, in the WLS dataset, we found for both men and women that emphasizing Family identity is important was also significantly positively associated with reproduction, among all ATVws explaining with $2.36 \%$ the highest proportion of the total variance in number of children. After Importance of family identity, the Importance to marry within someone's own religious (1.4\% MIDUS) and How close own religious group (1.16\% WLS) explained most of the variance among the 'identity indicators'.

If men and women are analyzed separately, in the WLS data, in men, the Importance of voluntary identity (variance explained $\sim 0.34 \%$ ) was also significantly positively associated with reproduction. This is particularly interesting, as we also know on the basis of the WLS data that in men but not in women 'doing voluntary work' is also significantly positively associated with number of children (Fieder \& Huber, 2012); thus, acting prosocially within a group appears to confer reproductive benefits to men only.

The results of religious in-group preference were in line with findings of census data from 32 countries worldwide (3.7 million couples) that in most of the countries being in a religious homogamous marriage is associated with increased reproduction (Fieder \& Huber, 2016), which also holds true for the WLS dataset (Fieder \& Huber, 2016). Interestingly, in the WLS dataset, the preference for a religious homogamous relationship explains more of the variance than the actual homogamy (Table 5).

Although the indicators of religious in-group preferences are predominantly associated with an increase in reproduction, all attitudes - only analyzed on the basis of the MIDUS sample - have to some extent a genetic predisposition, ranging from as low as $19 \%$ for How close is someone to his or her own race up to $46 \%$ for the Preference to marry someone from his or her own race. The genetic predisposition to Marry someone from own religion (i.e., the predisposition for religious homogamy) is considerably lower (around $23 \%$ ), whereas with around $40 \%$, the attitudes Identify own religious group and Identify ethnic group have a comparably high heritability. Generally, our heritability estimates are comparable with estimates based on the MIDUS and other datasets (Bradshaw \& Ellison, 2008; Lewis \& Bates, 2017; Lewis et al., 2014; Loehlin, 1993). 


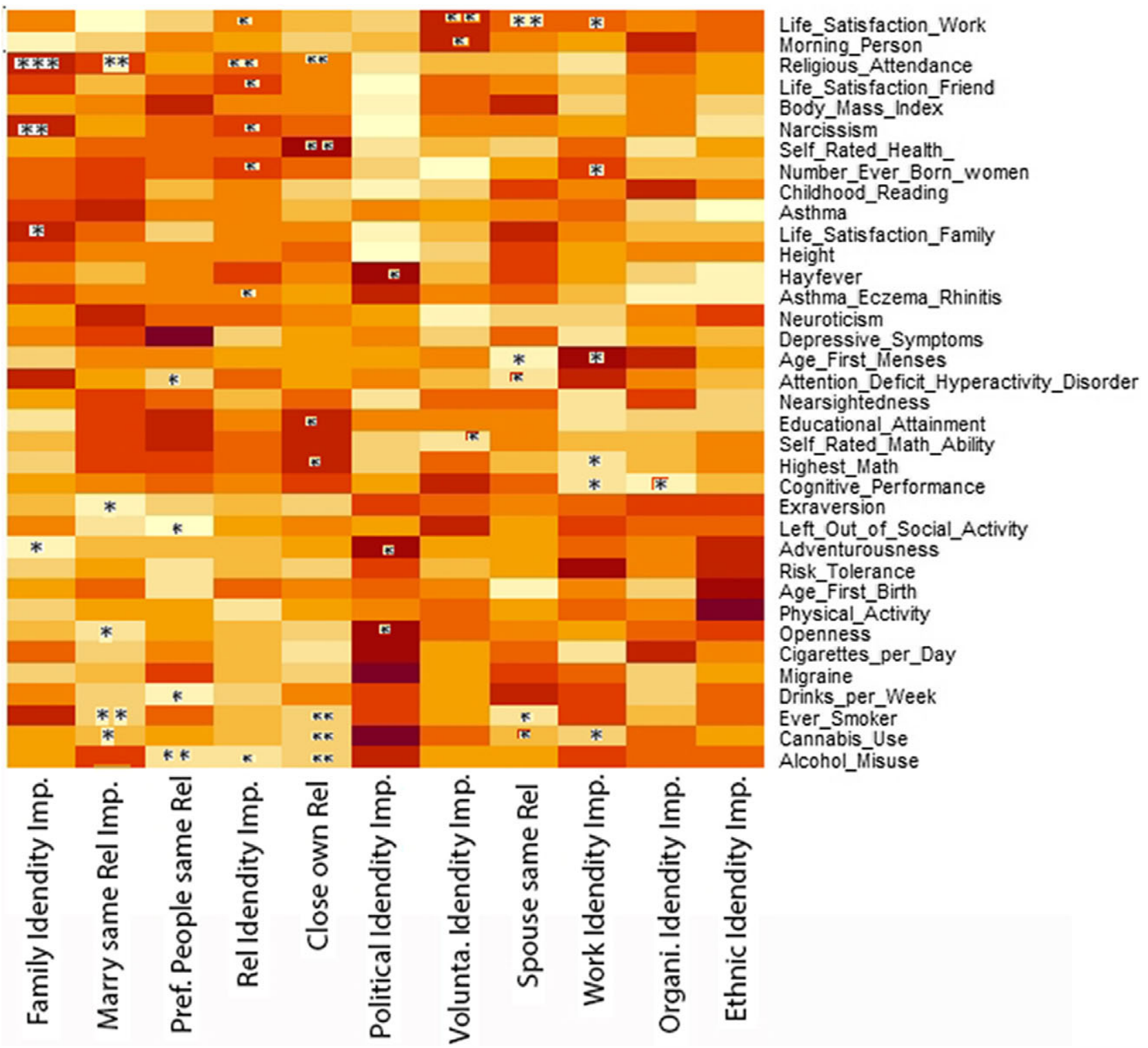

Fig. 1. Heatmap of the associations of all PGSs available for the WLS dataset with the ATVws. The darker the fields the more positive are the associations, the lighter the more negative. Regression coefficients and significances on the basis of a general linear model of the ATVws regressing on the PGSs, sex, age the first 10 principle components and the corresponding ATVws of the selected siblings.

Note: WLS, Wisconsin Longitudinal Study; PGSs, polygenic risk scores; ATVws, attitude variables.

$p$ values: ${ }^{\star}<.05,{ }^{\star \star}<.01,{ }^{\star \star \star}<.001$.

In the WLS, the recently available PGSs facilitated the analysis of the associations of these PGSs with the ATVws. Not surprisingly, the attitudes towards religious in-group and religious in-group marriage and also actual religious homogamy were significantly positively associated with the PGS of religious attendance (derived on the basis of $\sim 445.000$ individuals from the UK Biobank (UKB; Benjamin et al., 2021). Interestingly, this holds also true for the associations with 'Life Satisfaction - Work' (derived on the basis of $\sim 115.000$ Individuals from the UKB; Benjamin et al., 2021), where we found significant positive associations with How important is your religious identity, Spouse has the same religion, How important is your family identity and How important is your voluntary identity. This finding is in line with findings that more religious individuals are more pleased with their life (Bergan \& McConatha, 2001; Ellison et al., 1989).
Generally, all PGSs for addiction, such as alcohol misuse, cannabis use (UKB $\sim 144.000)$, ever smoker (UKB $\sim 446.000)$ and drinks per week (UKB $\sim 386.000$ ), were significantly negatively associated with some of the indicators of religious in-group preference, such as attitude towards religious in-group marriage and actual religious in-group marriage, indicating negative genetic associations of religious in-group behavior and addiction. Thus, having a predisposition for religious in-group behavior appears to be associated with a genetic predisposition against addictive behavior in a very broad sense, which might possibly to some extent be at the root of the strong prohibition of drugs and addictive behavior by religion (Porche et al., 2015; Richard et al., 2000).

Interestingly, the PGS of ADHD (Demontis et al., 2019, $\sim 35,000$ ) was significantly negatively associated with some religious in-group preference (How important are people same religion) and religious homogamy, whereas the PGS for narcissism 
Table 6. Associations of several PGSs with the ATVws. Only PGSs and ATVws are displayed with at least one significant association. Regression coefficients and significances are displayed on the basis of a general linear model of the ATVws regressing on the PGSs, sex, age the first 10 principle components and the corresponding ATVws of the selected siblings

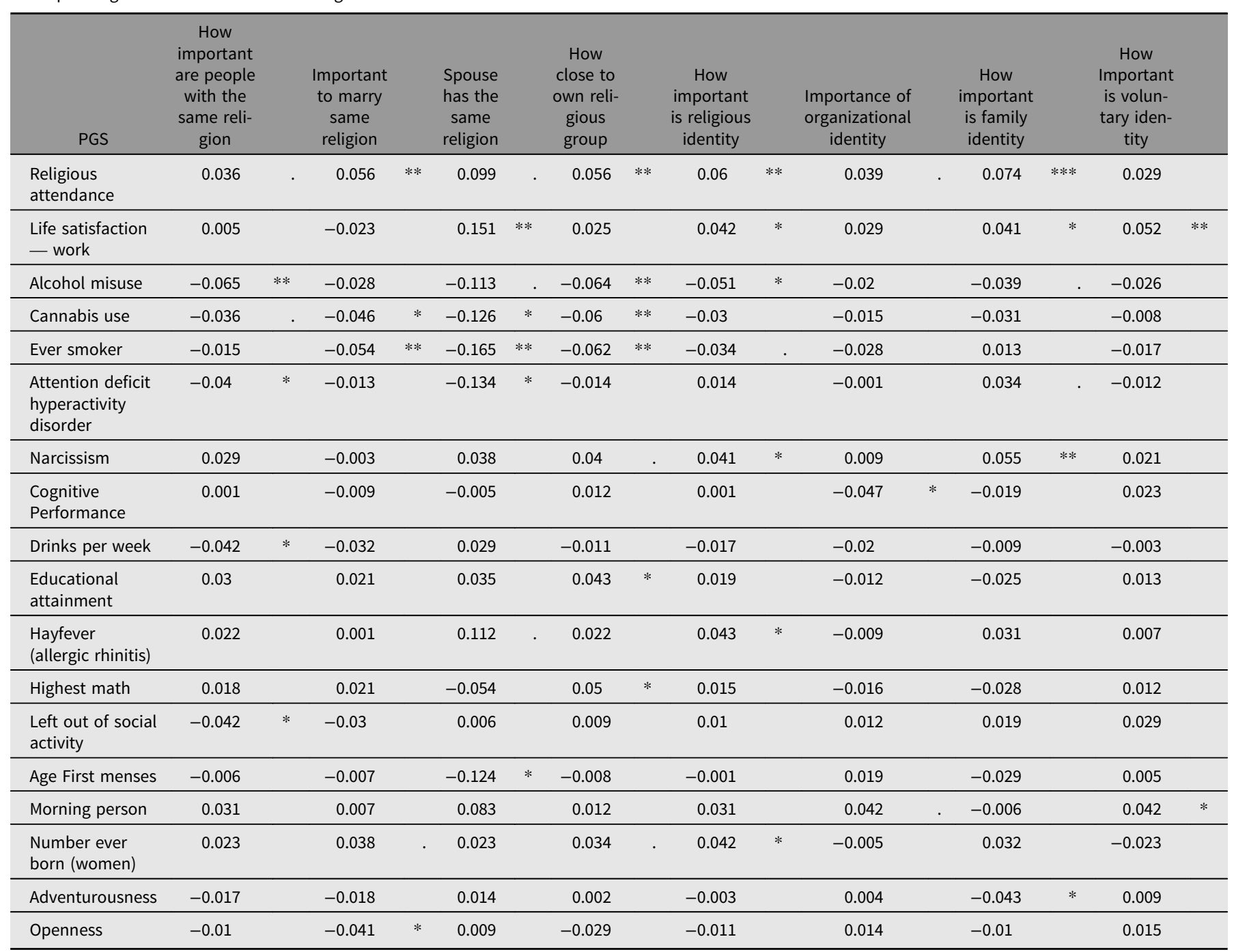

Note: PGS, polygenic scores; ATVws, attitude variables Wisconsin Longitudinal Study.

$p$ values: ${ }^{*}<.05,{ }^{\star \star}<.01,{ }^{\star \star *}<.001$, marginally significant $<.1$.

( 453,000; data from AddHealth, Dunedin, EGCUT, ELSA, E-Risk, HRS, MCTFR, Texas Twins, STR, WLS, UKB1, UKB2, UKB3) was significantly positively associated with the selfestimated importance of someone's religious identity and family identity. All other PGSs only show some single 'sporadic association' with some of the in-group phenotypes (Table 6). Regarding the PGSs for reproduction (i.e., age at first birth, number of children born for men and women; Barban et al., 2016), only a significant positive association between How important is religious identity and the PGS for the number of children born to women, as well as two marginally significant associations of the number of children born to women and Important to marry same religion and How close is own religious group emerged.

Our data show that although in-group attitudes generally have a reasonable genetic predisposition - as has been previously documented (Bradshaw \& Ellison, 2008; Lewis \& Bates, 2017; Lewis et al., 2014; Loehlin, 1993) — which also holds true for religious homogamy, only religious in-group preference as well as in-group marriage also provides reproductive benefits in terms of higher number of children in both datasets (although with some exceptions). As both religious in-group preferences and in-group marriage are associated with reproductive benefits and are heritable to some extent, it is thus reasonable to speculate on more recent selective forces for religious in-group attitudes. Although the variances in reproduction explained by in-group attitudes are comparably low in evolutionary timeframes, even low percentages acting for a very long period may have had a substantial selective pressure.

Big religions with 'big gods' did emerge during the Neolithic revolution, helping overcome tribal and racial borders and leading to the first states and thus to a 'bigger we' (Norenzayan \& Shariff, 2008; Purzycki et al., 2016). Accordingly, religions may have widened racial and ethnic borders by a replacement through the (reproductive) benefits of religious in-group attitudes. A potential former previous positive association of ethnic or racial in-group 
preferences and reproduction, if it ever existed, might be echoed in the heritable component of these preferences and the rather sporadic positive associations with reproduction, such as the association between men's preference for racial homogamy and number of children. Thus, we assume that selection on in-group preferences may have acted through the construction of a cultural niche (Laland et al. 2000), fostering religious in-group behavior and thus accelerating human evolution by a biocultural co-evolution in terms of reproductive benefits for those who are committed to their own religious group and those marrying and reproducing within their own religious group (Fieder \& Huber, 2016), thereby overcoming tribal and racial reproductive barriers (Huber \& Fieder, 2018) that may have hindered genetic and cultural exchange. Furthermore, the PGS correlations indicate that genetic predispositions for some traits (e.g., life satisfaction) are more compatible with religious in-group behavior than others (e.g., addiction). We can only speculate why this is the case. Maybe addiction, for instance, leads to increasing tensions within religious groups.

We conclude that in-group attitudes are heritable, and that primarily religious in-group attitudes provide reproductive benefits. However, both in-group attitudes and out-group attitudes may be rooted in our past and may have made sense from an evolutionary point of view because too pronounced in-group preference may have led to a higher frequency of inbreeding and accordingly to more and longer runs of homozygosity, with all the accompanied problems (Clark et al., 2019). In line with this, we recently succeeded to document on the basis of genetic data from the USA and Australia that indeed individuals with a more ethno-centristic attitude do have more and longer runs of homozygosity, presumably indicating a history of inbreeding (Fieder et al., 2021).

Supplementary material. To view supplementary material for this article, please visit https://doi.org/10.1017/thg.2021.48.

Acknowledgments. Prof. Nick Martin for his valuable comments and remarks on the manuscript. National Survey of Midlife in the United States (MIDUS), A National Longitudinal Study of Health \& Well-Being — publically available data from the MIDUS study was used for this research. Wisconsin Longitudinal Study (WLS), including graduates, siblings and spouses]: 19572019 Version 13.07. (machine-readable data file)/Hauser, Robert M., William H. Sewell and Pamela Herd. (principal investigators) from the University of Wisconsin-Madison.

Financial support. Since 1995 the MIDUS study has been funded by the following: John D. and Catherine T. MacArthur Foundation Research Network National Institute on Aging (P01-AG020166) National Institute on Aging (U19-AG051426).

\section{References}

Anthony, D. W. (2010). The horse, the wheel, and language. Princeton University Press.

Barban, N., Jansen, R., De Vlaming, R., Vaez, A., Mandemakers, J. J., Tropf, F. C., Shen, X., Wilson, J. F., Chasman, D. I., Nolte, I. M., Tragante, V., van der Laan, S. W., Perry, J. R., Kong, A.; BIOS Consortium, Ahluwalia, T. S., Albrecht, E., Yerges-Armstrong, L., Atzmon, G., ... Mills, M. C. (2016). Genome-wide analysis identifies 12 loci influencing human reproductive behavior. Nature Genetics, 48, 1462-1472.

Benjamin, D., Cesarini, D., Okbay, A., \& Turley, P. (2021). Polygenic Index Repository User Guide (version 1.0). https://www.ssc.wisc.edu/wlsresearch/ documentation/GWAS/PGIrepo_UserGuide_v1.0.pdf

Bergan, A., \& McConatha, J. T. (2001). Religiosity and life satisfaction. Activities, Adaptation \& Aging, 24, 23-34.
Bradshaw, M., \& Ellison, C. G. (2008). Do genetic factors influence religious life? Findings from a behavior genetic analysis of twin siblings. Journal for the Scientific Study of Religion, 47, 529-544.

Carlson, L. (2019). Homogamy in US Marriages, 2019. Family Profile No. 6, 2021. National Center for Family \& Marriage Research. https://www.bgsu. edu/ncfmr/resources/data/family-profiles/carlson-homogamy-marriages2019-fp-21-06.html

Chagnon, N. A. (2013). Noble savages: My life among two dangerous tribes The Yanomamo and the anthropologists. Simon and Schuster.

Clark, D. W., Okada, Y., Moore, K. H., Mason, D., Pirastu, N., Gandin, I., Mattsson, H., Barnes, C. L. K., Lin, K., Zhao, J. H., Deelen, P., Rohde, R., Schurmann, C., Guo, X., Giulianini, F., Zhang, W., Medina-Gomez, C., Karlsson, R., Bao, Y., . . W Wilson, J. F. (2019). Associations of autozygosity with a broad range of human phenotypes. Nature Communications, 10, 1-17.

Demontis, D., Walters, R. K., Martin, J., Mattheisen, M., Als, T. D., Agerbo, E., Baldursson, G., Belliveau, R., Bybjerg-Grauholm, J., Bækvad-Hansen, M., Cerrato, F., Chambert, K., Churchhouse, C., Dumont, A., Eriksson, N., Gandal, M., Goldstein, J. I., Grasby, K. L., Grove, J., ... Neale, B. M. (2019). Discovery of the first genome-wide significant risk loci for attention deficit/hyperactivity disorder. Nature Genetics, 51, 63-75.

Ellison, C. G., Gay, D. A., \& Glass, T. A. (1989). Does religious commitment contribute to individual life satisfaction? Social Forces, 68, 100-123.

Fieder, M., \& Huber, S. (2012). The association between pro-social attitude and reproductive success differs between men and women. PloS One, 7, e33489.

Fieder, M., \& Huber, S. (2016). The association between religious homogamy and reproduction. Proceedings of the Royal Society B: Biological Sciences, 283, 20160294.

Fieder, M., Mitchell, B. L., Gordon, S., Huber, S., \& Martin, N. G. (2021). Ethnic identity and genome wide runs of homozygosity. Behavior Genetics, 51, 405-413.

Glowacki, L., \& Wrangham, R. (2015). Warfare and reproductive success in a tribal population. Proceedings of the National Academy of Sciences, $112,348-353$.

Goldberg, A., Günther, T., Rosenberg, N. A., \& Jakobsson, M. (2017). Ancient X chromosomes reveal contrasting sex bias in Neolithic and Bronze Age Eurasian migrations. Proceedings of the National Academy of Sciences, 114, 2657-2662.

Haak, W., Lazaridis, I., Patterson, N., Rohland, N., Mallick, S.,Llamas, B., Brandt, G., Nordenfelt, S., Harney, E., Stewardson, K., Fu, Q., Mittnik, A., Bánffy, E., Economou, C., Francken, M., Friederich, S., Pena, R. G., Hallgren, F., Khartanovich, V., ... Fu, Q. (2015). Massive migration from the steppewas a source for Indo-European languages in Europe. Nature, 522, 207-211.

Hampshire, J. (2015). Europe's migration crisis. Political Insight, 6, 8-11.

Heaton, T. B. (1984). Religious homogamy and marital satisfaction reconsidered. Journal of Marriage and the Family, 46, 729-733.

Huber, S., \& Fieder, M. (2011). Educational homogamy lowers the odds of reproductive failure. PLoS One, 6, e22330.

Huber, S., \& Fieder, M. (2016). Worldwide census data reveal prevalence of educational homogamy and its effect on childlessness. Frontiers in Sociology, $1,10$.

Huber, S., \& Fieder, M. (2018). Mutual compensation of the effects of religious and ethnic homogamy on reproduction. American Journal of Human Biology, 30, e23064.

Huber, S., Zahourek, P., \& Fieder, M. (2017). Living with own or husband's mother in the household is associated with lower number of children: A cross-cultural analysis. Royal Society Open Science, 4, 170544.

Jantzen, D., Brinker, U., Orschiedt, J., Heinemeier, J., Piek, J.,Hauenstein, K., Krüger, J., Gundula Lidke, G., Lübke, H., Lampe, R., Lorenz, S., Schult, M., \& Lorenz, S. (2011). A Bronze Age battlefield? Weapons and trauma in the Tollense Valley, North-Eastern Germany. Antiquity, 85, 417-433.

Kalmijn, M. (1991). Shifting boundaries: Trends in religious and educational homogamy. American Sociological Review, 786-800.

Kandler, C., Lewis, G. J., Feldhaus, L. H., \& Riemann, R. (2015). The genetic and environmental roots of variance in negativity toward foreign nationals. Behavior Genetics, 45, 181-199. 
Laland, K. N., Odling-Smee, J., \& Feldman, M. W. (2000). Niche construction, biological evolution, and cultural change. Behavioral and Brain Sciences, 23, 131-146.

Lewis, G. J., \& Bates, T. C. (2017). The temporal stability of in-group favoritism is mostly attributable to genetic factors. Social Psychological and Personality Science, 8, 897-903.

Lewis, G. J., Kandler, C., \& Riemann, R. (2014). Distinct heritable influences underpin in-group love and out-group derogation. Social Psychological and Personality Science, 5, 407-413.

Loehlin, J. C. (1993). Nature, nurture, and conservatism in the Australian twin study. Behavior Genetics, 23, 287-290.

Mills, M. C., Barban, N., \& Tropf, F. C. (2020). An introduction to statistical genetic data analysis. MIT Press.

Norenzayan, A., \& Shariff, A. F. (2008). The origin and evolution of religious prosociality. Science, 322, 58-62.

Porche, M. V., Fortuna, L. R., Wachholtz, A., \& Stone, R. T. (2015). Distal and proximal religiosity as protective factors for adolescent and emerging adult alcohol use. Religions, 6, 365-384.

Purzycki, B. G., Apicella, C., Atkinson, Q. D., Cohen, E., McNamara, R. A., Willard, A. K., Xygalatas, D., Norenzayan, A., \& Henrich, J. (2016).
Moralistic gods, supernatural punishment and the expansion of human sociality. Nature, 530, 327-330.

Reich, D. (2018). Who we are and how we got here: Ancient DNA and the new science of the human past. Oxford University Press.

Richard, A. J., Bell, D. C., \& Carlson, J. W. (2000). Individual religiosity, moral community, and drug user treatment. Journal for the Scientific Study of Religion, 39, 240-246.

Schahbasi, A., Huber, S., \& Fieder, M. (2021). Factors affecting attitudes toward migrants - An evolutionary approach. American Journal of Human Biology, 33, e23435.

Sikora, M., Seguin-Orlando, A., Sousa, V. C., Albrechtsen, A., Korneliussen, T., Ko, A., Rasmussen, S., Dupanloup, I., Nigst, P. R., Bosch, M. D., Renaud, G., Allentoft, M. E., Margaryan, A., Vasilyev, S. V., Veselovskaya, E. V., Borutskaya, S. B., Deviese, T., Comeskey, D., Higham, T., ... Willerslev, E. (2017). Ancient genomes show social and reproductive behavior of early Upper Paleolithic foragers. Science, 358, 659-662.

van Bavel, J. (2012). The reversal of gender inequality in education, union formation and fertility in Europe. In Vienna Yearbook of Population Research (pp. 127-154). 